ISSN 0103-8478

\title{
Cultivo do champignon em função da temperatura
}

\author{
Buton mushroom cultivation in function of temperature
}

Vinícius Reis de Figueirêdo ${ }^{\mathrm{I}}$ Eustáquio Souza Dias ${ }^{\mathrm{II}}$

\section{RESUMO}

O cogumelo Agaricus bisporus é um cogumelo de clima temperado que requer baixa temperatura para a indução da frutificação. Essa exigência limita o seu cultivo no Brasil nos meses mais frios do ano ou exige a utilização de ambiente controlado, onerando muito a produção. Por isso, este trabalho teve como objetivo avaliar a produtividade de diferentes linhagens em função da temperatura de cultivo após a indução da frutificação. Diferentes linhagens de A. bisporus foram avaliadas quanto ao efeito da temperatura sobre a colonização do composto e a produtividade do cogumelo. As temperaturas de 21 e $25^{\circ} \mathrm{C}$ foram utilizadas durante a colonização do composto e, após a indução da frutificação, durante o ciclo de cultivo. Para todas as linhagens testadas, a temperatura de $25^{\circ} \mathrm{C}$ proporcionou maior velocidade de colonização do composto, favorecendo ciclos de cultivo mais curtos. Além disso, após a indução da frutificação a $18^{\circ} \mathrm{C}$, a manutenção do ambiente de cultivo a $25^{\circ} \mathrm{C}$ proporcionou maior produtividade, quando comparada ao cultivo a $21^{\circ} \mathrm{C}$. Para a linhagem mais produtiva, os três primeiros fluxos foram responsáveis por mais de $50 \%$ da produção total. Portanto, para um cultivo comercial em que é necessário manter volumes constantes de produção, os ciclos de cultivo poderiam ser limitados a três fluxos de produção.

Palavras-chave: champignon, crescimento micelial, fluxos de produção.

\section{ABSTRACT}

The Agaricus bisporus is a button mushroom that requires low temperature to induce fruiting. This requirement limits our cultivation in Brazil during the coldest months of the year and requires the use of controlled environment. Therefore, this study aimed to assess the productivity of different strains depending on the growth temperature after induction of fruiting. A. bisporus strains were evaluated for the effect of temperature on the colonization of compost and mushroom productivity. Temperatures of 21 and $25^{\circ} \mathrm{C}$ were used for the substrate colonization and after induction of fruiting crop cycle. For all strains tested, temperature $25^{\circ} \mathrm{C}$ gave a quickly colonization of the compound, favoring shorter production cycles. Furthermore, after induction of fruiting at $18^{\circ} \mathrm{C}$, maintaining the culture environment at $25^{\circ} \mathrm{C}$ gave a higher productivity to contrast with culture at $21^{\circ} \mathrm{C}$. For the most productive strain, the first three streams were responsible for over $50 \%$ of total production. Thus, for a cash crop where it is necessary to maintain constant volumes of production, crop cycles could be limited to three productions flows.

Key words: button mushroom, micelial growth, production flow.

\section{INTRODUÇÃO}

O Agaricus bisporus (Lange) Imbach, também conhecido como "champignon", lidera o ranking mundial de produção e consumo de cogumelos, com elevados índices de produtividade (SÁNCHEZ, 2010). Segundo CHOUDHARY (2011), o cultivo de A. bisporus contribui com 31,8\% da produção mundial de cogumelos. Entretanto, no Brasil, a produção ainda necessita de mais pesquisas para a expansão dessa atividade (DIAS, 2010). Por outro lado, o sucesso para a produção de cogumelos necessita aliar conhecimento científico com a experiência prática (CHOUDHARY, 2011).

A capacidade de o fungo crescer e produzir cogumelos em substratos lignocelulósicos está relacionada com o vigor do micélio e com a capacidade de ativar mecanismos fisiológicos, os quais secretam enzimas extracelulares (MATA et al.,

Instituto Federal de Educação, Ciência e Tecnologia Baiano (IF BAIANO), 45320-000, Santa Inês, BA, Brasil. E-mail: vinicius.figueiredo@si.ifbaiano.edu.br. Autor para correspondência.

"Universidade Federal de Lavras (UFLA), Lavras, MG, Brasil. 
2001). Entretanto, após a colonização do substrato, o fungo precisa de um fator de estresse para frutificar, como ocorre com os cogumelos de modo geral. Para o champignon, um dos principais fatores para indução da frutificação é a redução da temperatura, para imitar as condições naturais, uma vez que, na natureza, em países de clima temperado, a frutificação dos cogumelos normalmente ocorre quando se inicia a primavera, após um longo período de frio. Para este cogumelo, foi estabelecida uma temperatura entre 17 e $19^{\circ} \mathrm{C}$ para indução da sua frutificação (DIAS et al., 2004), a qual é mantida durante todo o ciclo de produção. A manutenção da temperatura abaixo de $20^{\circ} \mathrm{C}$ não é necessária para o desenvolvimento dos cogumelos, entretanto, permite determinado controle sobre o desenvolvimento de pragas e doenças. Para os países desenvolvidos, o ambiente de cultivo é possível com a utilização de uma infraestrutura de custo bastante elevado. Nesses países, o elevado custo de produção é compensado por uma produção contínua e elevada do cogumelo, sendo, por isso, considerada uma atividade industrial. A produção dos cogumelos em escala comercial depende, além das características genéticas, de fatores físicos, ambientais, químicos, nutritivos e microbiológicos (PARDO et al., 2002a, b).

Entretanto, essas instalações são inviáveis, principalmente para as condições do pequeno produtor no Brasil. Por isso, as estruturas de cultivo são, geralmente, bastante rústicas, contando com condições ambientais mais favoráveis, tais como elevada umidade relativa do ar e temperaturas amenas nas regiões de cultivo. Isso implica dizer que o cultivo de champignon no Brasil tem se limitado a áreas de clima ameno nas regiões sul e sudeste, de preferência, próximas a áreas de preservação ambiental com matas nativas ou reflorestadas. ANDRADE et al. (2010), analisando o crescimento micelial de $\boldsymbol{A}$. bisporus no Brasil observaram que a temperatura de $25^{\circ} \mathrm{C}$ demonstrou ser mais favorável ao crescimento, quando comparado com a temperatura de incubação a $20^{\circ} \mathrm{C}$. Portanto, as linhagens de $\boldsymbol{A}$. bisporus são influenciadas pela temperatura de incubação.

Por outro lado, apesar dessas condições favorecerem um baixo custo de produção, o produtor tem pouquíssimo controle sobre o seu ambiente de cultivo. Como exemplo, podemos citar produtores que, durante o período de colonização do composto, têm dificuldades de elevar a temperatura ambiente para favorecer uma colonização mais rápida. Como consequência, o tempo de colonização demora muito mais do que seria necessário, caso ele pudesse elevar a temperatura do ambiente. Diante disso, é importante que o pequeno produtor brasileiro utilize um pouco de tecnologia para a sua atividade, sem elevar sobremaneira o seu custo de produção. Nesse aspecto, um investimento numa infraestrutura simples que permita o acúmulo do calor e a redução da temperatura quando necessário poderia permitir ao produtor um melhor controle da sua atividade.

Nesse contexto, o estudo das linhagens de A. bisporus mais adaptadas a essas condições, bem como a resposta delas às variações de temperatura, é importante para dar ao pequeno produtor o suporte tecnológico necessário para melhorar a sua produção. Por isso, o objetivo deste estudo foi avaliar a influência da temperatura na velocidade de colonização do substrato de cultivo e na produtividade de diferentes linhagens de A. bisporus.

\section{MATERIAL E MÉTODOS}

Linhagens, meio de cultivo e produção do inoculante Foram utilizadas cinco linhagens de $\boldsymbol{A}$. bisporus, denominadas ABI-2, ABI-3, ABI-5, ABI-6 e ABI-7, disponíveis na Micoteca do Laboratório de Cogumelos Comestíveis da Universidade Federal de Lavras. As linhagens ABI-2, 3, 5, e 6 são linhagens cedidas pela Universidade Estadual de São Paulo (UNESP-BOTUCATU) e a linhagem ABI-7 é um material fornecido por um produtor comercial de Barbacena - MG (Sítio dos Micélios).

As linhagens foram reativadas em meio AAE (Agar arroz/extrato de levedura). Para o preparo do meio, utilizou-se $1 \mathrm{~kg}$ de arroz sem casca, o qual foi cozido durante 15 minutos em água fervente. A seguir, 1L do caldo foi utilizado, no qual adicionou-se $15 \mathrm{~g}$ de Agar e, $15 \mathrm{~g}$ Extrato de Levedura. O meio foi autoclavado a $121^{\circ} \mathrm{C} / 30$ minutos. Após o resfriamento, o meio foi vertido em placas de Petri (20mL placa $\left.{ }^{-1}\right)$. Em seguida, as linhagens foram inoculadas nas placas e incubadas a $25^{\circ} \mathrm{C} \pm 1$ / 14 dias para obtenção do inoculo inicial. Após o período de incubação, o inoculo primário foi incubado em frascos de vidro com capacidade de $500 \mathrm{~mL}$, contendo grãos de trigo e água destilada (v:v), adicionado de 3\% de carbonato de cálcio e incubado a $25^{\circ} \mathrm{C} \pm 1 / 30$ dias, obtendo-se o spawn.

\section{Substrato de cultivo e camada de cobertura}

O composto foi preparado conforme procedimentos padrões para a espécie, baseado em bagaço de cana, palha de arroz, cama de frango e esterco de cavalo, os quais foram empilhados alternadamente e irrigados em abundância. A cada 48 horas, a pilha era revirada para proporcionar maior 
homogeneização do substrato. Após a 3a reviragem, foram incorporados ao substrato o farelo de soja, ureia, cloreto de potássio, superfosfato simples e gesso agrícola. O processo de compostagem durou 18 dias. Em seguida, o composto foi pasteurizado a $58^{\circ} \mathrm{C}$ durante 20 horas. A fase seguinte foi o condicionamento, no qual o composto foi mantido durante 6 dias a uma temperatura entre $50-52^{\circ} \mathrm{C}$. Imediatamente após essa fase, o composto foi resfriado à temperatura ambiente (em torno de $30^{\circ} \mathrm{C}$ ) e acondicionado em sacos de polipropileno com capacidade de $15 \mathrm{~kg}$. O composto foi inoculado na parte superior e incubado em salas climatizadas, em dois ambientes com temperaturas de $25 \pm 1$ e $21 \pm 1^{\circ} \mathrm{C}$ durante 14 dias.

Foi realizado um teste preliminar em condições de laboratório, utilizando diferentes temperaturas para crescimento de linhagens de $\boldsymbol{A}$. bisporus.

Avaliou-se o crescimento micelial no substrato de cultivo $(\mathrm{cm})$ a cada 48 horas até a colonização completa do substrato, bem como o tempo de colonização deste (em dias).

Foi utilizada uma camada de cobertura contendo Gleissolo húmico, Latossolo vermelho distroférrico e calcário calcítico (v:v), a qual foi adicionada após 14 dias, quando o micélio já tinha colonizado totalmente o substrato de cultivo. Sete dias após a adição da camada de cobertura, os tratamentos foram incubados a $18^{\circ} \pm 1^{\circ} \mathrm{C}$, durante 10 semanas. Foi avaliado o tempo de colonização da camada de cobertura e a precocidade para início da produção para as diferentes linhagens testadas (em dias). Para o cultivo, foram analisados 10 fluxos de produção, os quais se dividiram em 10 semanas ininterruptas.

\section{Eficiência biológica e produtividade}

As avaliações da eficiência biológica e produtividade foram obtidas em percentagem através das fórmulas:

Eficiência biológica = (massa dos cogumelos frescos $/$ massa do composto desidratado) x 100 .

Produtividade $=$ (massa dos cogumelos frescos $/$ massa do composto úmido) x 100.

Delineamento experimental

Para a análise estatística, utilizou-se o programa SISVAR-UFLA, com delineamento em blocos casualizados, em esquema fatorial 5x2, no qual os tratamentos corresponderam às variações das cinco linhagens com as duas temperaturas testadas, totalizando dez tratamentos. Para cada tratamento, foram utilizadas seis repetições. Desse modo, utilizouse um total de 60 sacos (15kg), os quais representaram cada tratamento. Os dados foram submetidos à análise de variância e as médias foram comparadas pelo teste de Scott-Knott (5\%) (ANDRADE et al., 2010).

\section{RESULTADOS E DISCUSSÃO}

Em teste preliminar, avaliou-se o crescimento micelial de $\boldsymbol{A}$. bisporus em meio de cultura a diferentes temperaturas de incubação, verificando-se que o melhor crescimento micelial foi obtido em temperaturas superiores a $23^{\circ} \mathrm{C}$ (Tabela 1). Esses resultados já indicavam que, apesar do $\boldsymbol{A}$. bisporus requerer temperatura abaixo de $20^{\circ} \mathrm{C}$ para a sua frutificação e ser originado de um país de clima temperado, o seu crescimento vegetativo é favorecido por temperaturas acima dos $20^{\circ} \mathrm{C}$.

Posteriormente, foi avaliado o crescimento micelial de diferentes linhagens do fungo no substrato de cultivo em duas temperaturas (21 e $25^{\circ} \mathrm{C}$ ). Novamente, observou-se que o crescimento micelial foi superior em temperatura mais elevada $\left(25^{\circ} \mathrm{C}\right)$, para todas as linhagens testadas. $\mathrm{O}$ ganho na velocidade de crescimento micelial foi de $0,59 \mathrm{~cm} \mathrm{dia}^{-1}$ para ABI7, sendo a linhagem com melhor crescimento. Esses resultados mostram que, se o produtor utilizar uma linhagem adequada e puder controlar a temperatura do seu ambiente de cultivo, o composto de cultivo do cogumelo será colonizado em período menor de tempo, permitindo maior número de ciclos de cultivo ao longo do período. Segundo SILVA et al. (2005), a temperatura, além de outros fatores, pode influenciar na taxa de produção de cogumelos, pois está diretamente relacionada com a biomassa micelial formada durante o crescimento fúngico.

A $25^{\circ} \mathrm{C}$, a colonização completa do composto ocorreu em 13 dias, enquanto que, a $21^{\circ} \mathrm{C}$, a colonização completou-se em 24 dias, ou seja, 11 dias a mais, para a linhagem com maior velocidade de colonização (ABI-7). Além da colonização

Tabela 1 - Crescimento micelial de $\boldsymbol{A}$. bisporus em função de diferentes temperaturas em placas de Petri.

\begin{tabular}{lc}
\hline Temperatura $\left({ }^{\circ} \mathrm{C}\right)$ & Crescimento micelial $\left(\mathrm{mm} \mathrm{dia}^{-1}\right)^{* *}$ \\
\hline 17 & $1, .77 \mathrm{~d}$ \\
20 & $1.97 \mathrm{c}$ \\
$\mathrm{TA}^{*}(21,5)$ & $2.23 \mathrm{~b}$ \\
23 & $2.38 \mathrm{a}$ \\
28 & $2.43 \mathrm{a}$ \\
\hline
\end{tabular}

Médias seguidas de letras distintas na coluna são diferentes entre si pelo teste de Scott-Knott $(\mathrm{P}<0,05)$.

*TA: temperatura ambiente; **média de crescimento das linhagens testadas. 
do substrato de cultivo mais acelerada, podemos observar ainda uma maior precocidade na colheita, em função da colonização mais rápida da camada de cobertura para as linhagens que foram submetidas à temperatura de $25^{\circ} \mathrm{C}$ na fase de colonização do substrato, o que demonstra a importância do controle da temperatura na fase de crescimento vegetativo do fungo, proporcionando o lançamento de primórdios precocemente e reduzindo assim o ciclo de produção (Tabela 2).

De acordo com PARDO et al. (2010), há indícios de que, para a maioria das linhagens de $\boldsymbol{A}$. bisporus, o melhor crescimento vegetativo ocorre quando a temperatura do ar é mantida em torno de $24^{\circ} \mathrm{C}$. Entretanto, segundo os mesmos autores, para a indução da frutificação, a temperatura deve ser reduzida para $18^{\circ} \mathrm{C}$. Por outro lado, segundo LARGETEAU et al (2011), isolados selvagens de $\boldsymbol{A}$. bisporus têm potencial para a frutificação mesmo a $25^{\circ} \mathrm{C}$. Isso permitiria manter as câmaras de cultivo com a temperatura estável a $25^{\circ} \mathrm{C}$ durante todo o ciclo de produção, entretanto, esses isolados não são tão produtivos quanto as linhagens comerciais atualmente utilizadas. Por isso, para as condições brasileiras, talvez o ideal fosse utilizar duas temperaturas, uma para a indução da frutificação $\left(18^{\circ} \mathrm{C}\right)$ e outra para o crescimento dos cogumelos, durante o restante do ciclo de cultivo $\left(25^{\circ} \mathrm{C}\right)$.

As mesmas temperaturas utilizadas para avaliar a colonização do composto pelas linhagens de A. bisporus foram também utilizadas para a produção dos cogumelos, após induzir a frutificação a $18^{\circ} \mathrm{C}$. O composto que foi mantido a $25^{\circ} \mathrm{C}$ lançou primórdios com 29 dias após a inoculação, enquanto que o composto cultivado a $21^{\circ} \mathrm{C}$ apresentou os primeiros primórdios após 41 dias da inoculação, considerando a linhagem com maior velocidade de colonização
(ABI-7). Diante disso, é possível afirmar que os primórdios dos cogumelos são mais tardios quando o substrato é mantido à temperatura de $21^{\circ} \mathrm{C}$ na fase de colonização do substrato de cultivo.

Da mesma forma como observado para a velocidade de colonização do composto de cultivo, a temperatura de $25^{\circ} \mathrm{C}$ também favoreceu maior produtividade e eficiência biológica para todas as linhagens testadas, com ganhos de produtividade que variaram de 7.7 a 51.4\% (Tabela 3). A linhagem ABI-7, que apresentou maior velocidade de colonização do composto, apresentou também os melhores resultados de produtividade e EB nas duas temperaturas testadas, com 14,7 e 17,8\%, respectivamente. Para esta linhagem, o ganho de produtividade na temperatura de $25^{\circ} \mathrm{C}$ foi $20,7 \%$.

A linhagem ABI-6 apresentou o segundo melhor desempenho na colonização do composto de cultivo, entretanto, a produtividade alcançada foi a menor dentre todas as linhagens, tanto a 21 como a $25^{\circ} \mathrm{C}$. Esses resultados permitem inferir que nem sempre uma linhagem agressiva na colonização do composto de cultivo, apresentará também o melhor desempenho na produtividade. Coincidentemente, a linhagem com o melhor desempenho de colonização, apresentou também a melhor produtividade (linhagem ABI-7), entretanto, os resultados demonstraram que não há uma correlação direta entre os dois parâmetros avaliados.

Apesar dos melhores resultados obtidos com a temperatura de $25^{\circ} \mathrm{C}$, isso não significa que temperaturas mais elevadas sejam também favoráveis à produção de cogumelos. Esta inferência poderia ser feita, uma vez que o aumento da temperatura proporciona aumento da atividade enzimática, a qual, por sua vez, auxilia na degradação dos compostos presentes no substrato. Por outro lado,

Tabela 2 - Média diária de crescimento micelial no substrato de cultivo (CM), Crescimento no substrato de cultivo (CSC), Colonização da camada de cobertura (CCC), e precocidade (PRE) quando o cogumelo A. bisporus foi cultivado em diferentes temperaturas.

\begin{tabular}{|c|c|c|c|c|c|c|c|c|}
\hline \multirow{2}{*}{ Linhagens } & \multicolumn{2}{|c|}{ 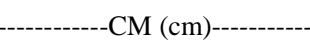 } & \multicolumn{2}{|c|}{ - } & \multicolumn{2}{|c|}{ (CCC)** } & \multicolumn{2}{|c|}{ - } \\
\hline & $21 \pm 1^{\circ} \mathrm{C}$ & $25 \pm 1^{\circ} \mathrm{C}$ & $21^{\circ} \mathrm{C}$ & $25^{\circ} \mathrm{C}$ & $21^{\circ} \mathrm{C}$ & $25^{\circ} \mathrm{C}$ & $21^{\circ} \mathrm{C}$ & $25^{\circ} \mathrm{C}$ \\
\hline ABI-2 & $0,400 \mathrm{Cb}$ & $0,720 \mathrm{Da}$ & $31 \mathrm{Da}$ & $20 \mathrm{Db}$ & $20 \mathrm{Ca}$ & $18 \mathrm{Cb}$ & $51 \mathrm{Da}$ & $38 \mathrm{Db}$ \\
\hline ABI-3 & $0,415 \mathrm{Cb}$ & 0,710Da & $30 \mathrm{Ca}$ & $19 \mathrm{Cb}$ & $20 \mathrm{Ca}$ & $18 \mathrm{Cb}$ & $50 \mathrm{Ca}$ & $37 \mathrm{Cb}$ \\
\hline ABI-5 & $0,445 \mathrm{Cb}$ & 0,760Ca & $30 \mathrm{Ca}$ & $19 \mathrm{Cb}$ & $20 \mathrm{Ca}$ & $18 \mathrm{Cb}$ & $50 \mathrm{Ca}$ & $37 \mathrm{Cb}$ \\
\hline ABI-6 & $0,490 \mathrm{Bb}$ & $0,815 \mathrm{Ba}$ & $28 \mathrm{Ba}$ & $17 \mathrm{Bb}$ & $18 \mathrm{Ba}$ & $17 \mathrm{Bb}$ & $46 \mathrm{Ba}$ & $34 \mathrm{Bb}$ \\
\hline ABI-7 & $0,950 \mathrm{Ab}$ & $1,540 \mathrm{Aa}$ & $24 \mathrm{Aa}$ & $13 \mathrm{Ab}$ & $17 \mathrm{Aa}$ & $16 \mathrm{Ab}$ & $41 \mathrm{Aa}$ & $29 \mathrm{Ab}$ \\
\hline
\end{tabular}

Médias seguidas de letras distintas nas colunas são diferentes entre si pelo teste de Scott-Knott $(\mathrm{P}<0,05)$.

Médias seguidas de letras distintas nas linhas, para cada parâmetro analisado (CM, CSC, CCC e, PRE), são diferentes entre si pelo teste de Scott-Knott $(\mathrm{P}<0,05)$.

*tempo em dias, desde a inoculação; **tempo, em dias, desde a adição da camada de cobertura. 
Tabela 3 - Valores de produtividade e eficiência biológica quando o cogumelo A. bisporus foi cultivado em diferentes temperaturas.

\begin{tabular}{|c|c|c|c|c|}
\hline \multirow{2}{*}{ Linhagens } & & - & --- & a-- \\
\hline & $\left(21 \pm 1^{\circ} \mathrm{C}\right)$ & $\left(25 \pm 1^{\circ} \mathrm{C}\right)$ & $\left(21 \pm 1^{\circ} \mathrm{C}\right)$ & $\left(25 \pm 1^{\circ} \mathrm{C}\right)$ \\
\hline ABI-2 & 7,80 Cb & $8,40 \mathrm{Ca}$ & $24,68 \mathrm{Cb}$ & $26,58 \mathrm{Ca}$ \\
\hline ABI-3 & $5,55 \mathrm{Db}$ & $7,08 \mathrm{Da}$ & $17,55 \mathrm{Db}$ & $22,42 \mathrm{Da}$ \\
\hline ABI-5 & $8,15 \mathrm{Bb}$ & $10,78 \mathrm{Ba}$ & $25,78 \mathrm{Bb}$ & $34,11 \mathrm{Ba}$ \\
\hline ABI-6 & 1,83 Eb & 2,77 Ea & 5,80 Eb & 8,76 Ea \\
\hline ABI-7 & $14,74 \mathrm{Ab}$ & $17,80 \mathrm{Aa}$ & 46,65 Ab & 56,32 Aa \\
\hline
\end{tabular}

Médias seguidas de letras distintas nas colunas são diferentes entre si pelo teste de Scott-Knott $(\mathrm{P}<0,05)$.

Médias seguidas de letras distintas nas linhas, para cada parâmetro analisado (produtividade e eficiência biológica), são diferentes entre si pelo teste de Scott-Knott $(\mathrm{P}<0,05)$.

temperaturas muito extremas podem comprometer o desenvolvimento do micélio através da inativação de enzimas e a síntese de vitaminas e ainda podem provocar deformações no cogumelo (MATA et al., 2001, COLAUTO et al., 2008).

Considerando que os melhores resultados foram obtidos com a temperatura de $25^{\circ} \mathrm{C}$, esses dados foram utilizados para se fazer o cálculo de produção por fluxo durante o ciclo de cultivo. Foram analisados 10 fluxos de produção para todas as linhagens, as quais atingiram mais de $50 \%$ de produção ainda no terceiro fluxo (Figura 1). De acordo com RINKER (1993), em um cultivo típico no Canadá, com 3 fluxos de produção, os dois primeiros fluxos de produção são responsáveis por cerca de $83 \%$ do total de cogumelos colhidos, enquanto que o terceiro fluxo é responsável por apenas 17\% desse total. Portanto, as condições mais rústicas utilizadas no Brasil ainda não permitem ciclos de cultivo tão curtos como relatado por RINKER (1993). Provavelmente, a utilização de turfa de alta qualidade e o controle rigoroso do ambiente de cultivo favoreça uma resposta tão rápida do cogumelo, permitindo um cultivo em escala industrial.

A linhagem ABI-7 alcançou 61,49\% da produção total nos três fluxos iniciais. Esta linhagem, portanto, além dos melhores resultados de colonização e produtividade, apresenta também maior potencial para utilização em ciclos mais curtos de produção, os quais são muito importantes para manter o escalonamento da produção e a demanda do mercado, além de prevenir a incidência de pragas e

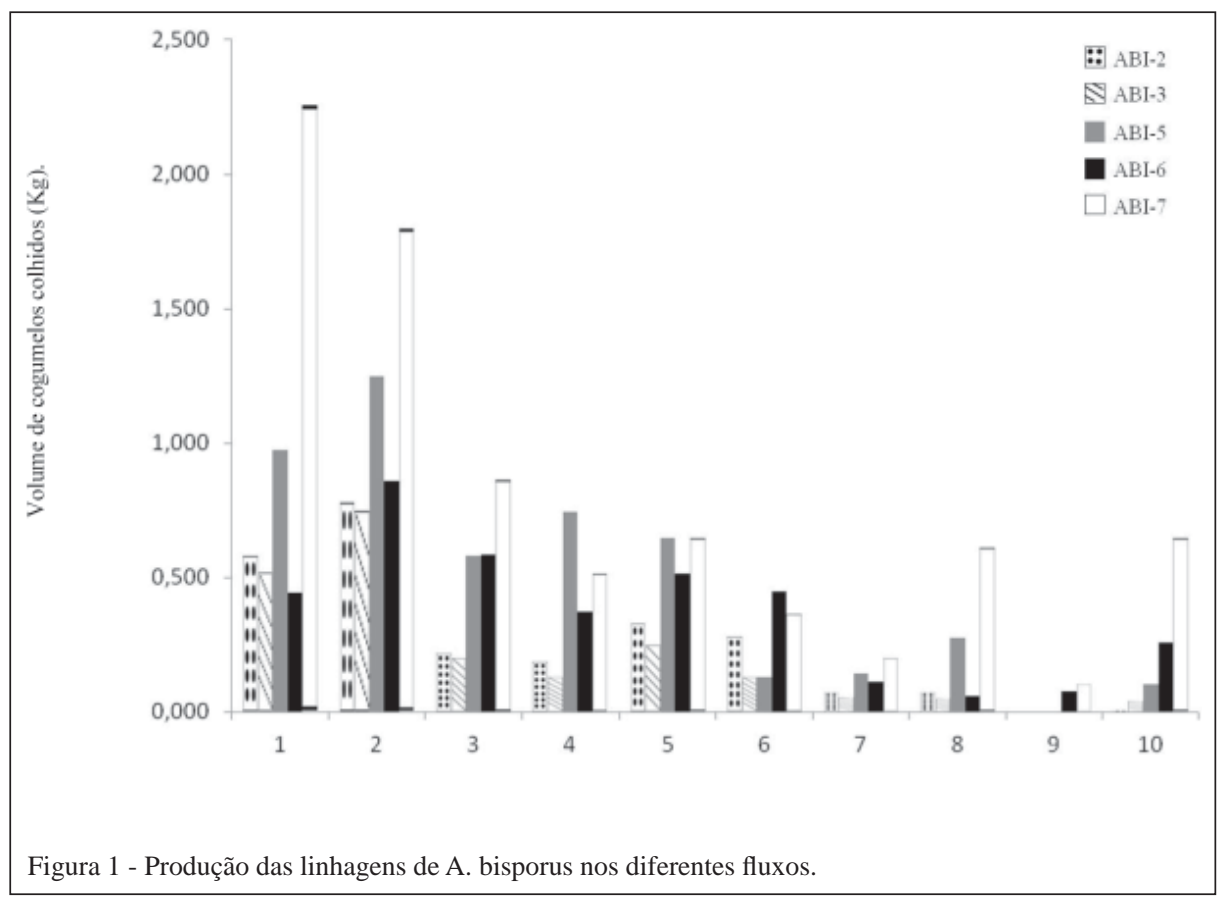

Ciência Rural, v.44, n.2, fev, 2014. 
doenças (PEÑARANDA et al., 2009). A utilização de ciclos com 3 fluxos de produção poderão ser muito importantes, não apenas para manter as metas de produção como também para permitir a redução ou a eliminação do uso de pesticidas, os quais são comuns nos cultivos longos como os observados no Brasil. Por isso, a linhagem ABI-7 será utilizada para estudos futuros, visando a novas técnicas de manejo que permitam picos maiores de produção nos 3 primeiros fluxos. Estudos futuros deverão ser conduzidos com o objetivo de se alcançar os níveis de produção desejados nos três fluxos iniciais.

\section{CONCLUSÃO}

O crescimento de A. bisporus sofreu influência da temperatura na fase de incubação, uma vez que a temperatura de $25^{\circ} \mathrm{C}$ proporcionou maior velocidade de colonização e maior produtividade do cogumelo. A temperatura de $25^{\circ} \mathrm{C}$ foi mais favorável para o crescimento micelial de todas as linhagens de $\boldsymbol{A}$. bisporus. A linhagem a ABI-7 é a mais produtiva, sendo, portanto, selecionada para os experimentos futuros.

\section{AGRADECIMENTOS}

À Universidade Federal de Lavras, à Fundação de Amparo à Pesquisa de Minas Gerais (FAPEMIG), à Coordenação de Aperfeiçoamento de Pessoal de Nível Superior (CAPES processo 5083/11-7) e ao Instituto Federal de Educação, Ciência e Tecnologia Baiano, pela infraestrutura concedida e pelo apoio financeiro.

\section{REFERÊNCIAS}

ANDRADE, M.C.N. et al. Crescimento micelial in vitro de cinco linhagens de Agaricus bisporus submetidas a diferentes condições de temperatura. Acta Scientiarum Agronomy, v.32, n.1, p.6972, 2010. Disponível em: <http://www.scielo.br/pdf/asagr/ v32n1/v32n1a10.pdf>. Acesso em: 28 nov. 2011 doi: 10.4025/ actasciagron.v32i1.333.

CHOUDHARY, D.K. First preliminary report on isolation and characterization of novel Acinetobacter spp. in casing soil used for cultivation of button mushroom, Agaricus bisporus (Lange) Imbach. International Journal of Microbiology, v.2011, p.6, 2011. Disponível em: <http://www.hindawi.com/journals/ ijmb/2011/790285/cta/>. Acesso em: 14 set. 2011. doi: 10.1155/2011/790285.

COLAUTO, N.B. Temperature and $\mathrm{pH}$ conditions for mycelial growth of Agaricus brasiliensis on axenic cultivation. Semina: Ciências Agrárias, v.29, n.2, p.307-312, 2008.
DIAS, E.S. et al. Truths and myths about the mushroom Agaricus blazei. Scientia Agricola, v.61, p.545-549, 2004. Disponível em: $<$ http://www.scielo.br/scielo.php?script=sci_arttext\&pid=S010390162004000500014\&lng=en\&nrm=iso>. Acesso em: 29 nov. 2012. doi: 10.1590/S0103-90162004000500014.

DIAS, E.S. Mushroom cultivation in Brazil: challenges and potential for growth. Ciência e Agrotecnologia, v.34, n.4, p.795-803, 2010. Disponível em: <http://www.scielo.br/scielo. php?script=sci_arttext\&pid=S1413-70542010000400001\&lng= en\&nrm=iso>. Acesso em: 29 nov. 2012. doi: 10.1590/S141370542010000400001.

MATA, G. et al. Selection of strains of Lentinula edodes and Lentinula boryana adapted for efficient mycelial growth on wheat straw. Revista Iberoamericana de Micologia, v.18, n.1, p.118-122, 2001. Disponível em: http://www.ncbi.nlm.nih.gov/ pubmed/15487920. Acesso em: 11 jan. 2012.

LARGETEAU, M.L. et al. Diversity in the ability of Agaricus bisporus wild isolates to fruit at high temperature $\left(25^{\circ} \mathrm{C}\right)$. Fungal Biology, v.115, n.11, p.1186-1195, 2011. Disponível em: <http:// www.sciencedirect.com/science/article/pii/S1878614611001565>. Acesso em: 04 fev 2012. doi: 10.1016/j.funbio.2011.08.004.

PARDO A. et al. Factores que influyen en la iniciación de la fructificación del champiñón cultivado. I. Factores físicos y ambientales. Factores químicos y nutritivos. ITEA, v.98, n.1, p.33-43, 2002a. Disponível em: <http://periodicos.uem.br/ojs/ index.php/ActaSciAgron/issue/view/390/showToc>. Acesso em: 04 fev 2012. doi: 10.4025/actasciagron.v32i1.333.

PARDO A. et al. Factores que influyen en la iniciación de la fructificación del champiñón cultivado. II. Factores microbiológicos. ITEA, v.98, n.2, p.87-94, 2002b. Disponível em: <http://periodicos.uem.br/ojs/index.php/ActaSciAgron/issue/ view/390/showToc >. Acesso em: 04 fev 2012. doi: 10.4025/ actasciagron.v32i1.333.

PARDO, A. et al. Utilización de compost agotado de champiñón como capa de coberturas en nuevos ciclos de producción. Pesquisa Agropecuária Brasileira, v.45, p.1164-1171, 2010. Disponível em: <http://www.scielo.br/pdf/pab/v45n10/16.pdf>. Acesso em: 13 abr. 2012.

PEÑARANDA, J.A.P. et al. Guía de implantación del sistema de análisis de peligros y puntos de control crítico (APPCC) en la producción, transformación y comercialización del champiñón y otros hongos comestibles cultivados. Cuenca: Patronato de Desarrollo Provincial, 2009. 522p.

SÁNCHEZ, C. Cultivation of Pleurotus ostreatus and other edible mushrooms. Applied Microbiology and Biotechnology, v.85, n.5, p.1321-1337, 2010. Disponível em: <http://www.ncbi. nlm.nih.gov/pubmed/19956947>. Acesso em: 22 maio, 2012.

SILVA, E.M. et al. Effect of cereal brans on Lentinula edodes growth and enzyme activities during cultivation on forestry waste. Letter in Applied Microbiology, v.40, n.4, p.283-288, 2005. 